\title{
Biological Responses to Change in Prehistoric Viet Nam
}

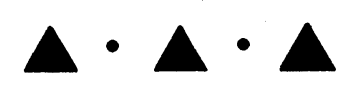

MARC OXENHAM

This PAPER EXAMINES A RANGE OF SKELETAL AND DENTAL PALAEOHEALTH markers in order to develop a picture of the lifeways and general well-being or health of the inhabitants of northern Viet Nam from the mid-Holocene through to adoption of bronze and iron technologies. Southeast Asian bioarchaeological inquiry has recently benefited from some exceptional studies (e.g., Domett 2001; Pietrusewsky and Douglas 2003; Tayles 1999), and while the geographic focus has been on Thailand, a new overview of migration, microevolutionary change, and palaeohealth in Southeast Asia is now available (Oxenham and Tayles 2006). Nonetheless, Viet Nam remains underresearched in terms of the archaeology of human biology. Until recently, most studies of Vietnamese human skeletal material have examined only late Pleistocene and Holocene morphology, patterns of microevolutionary change, and population movement within East Asia (Bulbeck et al. 2003; Demeter 1999; Demeter et al. 2000; Matsumura et al. 2001; K. T. Nguyen 1990, 1998; L. C. Nguyen 1985, 1992, 1996; Olivier 1966; Pietrusewsky 1988; Pietrusewsky et al. 1992).

The purpose of this paper is to compare and contrast the health and skeletally sensitive behaviors of prehistoric and protohistoric samples from northern Viet Nam in the context of extensive economic, demographic, and social changes occurring between approximately 6000 and 2000 years B.P. This study focuses on the results of a range of oral health and behavioral markers in addition to physiological well-being in the form of cribra orbitalia and linear enamel hypoplasia. Relevant work from previous publications addressing the issues of trauma and infectious disease in the samples is also summarized and discussed.

\section{THE BIOCULTURAL CONTEXT}

The following summary of the geography of the study region, drawn from T. D. Nguyen (1995), while not necessarily fully representative of conditions several thousand years ago, provides a generalized environmental context. Topographically, while about three-quarters of Viet Nam can be described as mountainous,

Marc F. Oxenham is with the School of Archaeology and Anthropology, Australian National University, Canberra, ACT.

Asian Perspectives, Vol. 45, No. 2 (C) 2006 by the University of Hawai'i Press. 
85 percent of the country is below $1000 \mathrm{~m}$ in elevation. Viet $\mathrm{Nam}$ has three plains systems that are still in the process of expansion. The archaeological sites of interest here are situated in the low-lying northern Bac Bo plain and fall between latitudes $18^{\circ}$ and $22^{\circ}$ north.

Viet Nam presents two distinct climatic zones: a northern and a southern. Northern Viet Nam has two seasons-cold and hot-but with high levels of humidity occurring during both periods. Further, in comparison to southern Viet Nam, the north experiences marked climatic variability or instability that has restricted levels of ecological variation. The country is prone to typhoons and has experienced over 400 during the last hundred years. Storms are also very frequent, with winds reaching up to $50 \mathrm{~m} / \mathrm{sec}$. This in combination with rainfall in excess of $600 \mathrm{~mm}$ in a 24 -hour period can lead to extensive agricultural and human disruption.

Because the Bac Bo region is essentially subtropical, tropical forests are found only below about $500 \mathrm{~m}$, while more tropical flora is found only below some $300 \mathrm{~m}$. Around the coastal regions mangroves still predominate, while dense bamboo forests are common all over the northern plains. The north is home to a diverse range of bird, riverine, and marine life. Some 900 species of fish are recognized in the Gulf of Bac Bo alone. Terrestrial animals such as sambar deer, muntjac, chamois, and numerous arboreal primates are still common in the region. In the past, elephants, rhinoceros, tigers, and panthers were also common.

\section{THE DA BUT PERIOD}

Da But period sites are located along the Ma River in Thanh Hoa Province, northern Viet Nam. The Da But is considered one of a number of emergent Neolithic cultures with a coastal/marine economic focus that developed out of the Hoabinhian culture approximately 6500 to 6000 years B.P. and existed for 1700 years (Bui Vinh 1991, 1994, 1996; K. S. Nguyen 1997). Communities making up the Hoabinhian period, dated to between 18,000 and 6000 years B.P., were involved in hunting and gathering a wide variety of mammals, birds, fish, and shellfish (Gorman 1971; Higham 1989). The relationship between these emergent post-Hoabinhian cultures and the Hoabinhian itself is unclear. Hoabinhian sites are generally restricted to inland caves and rock shelters in Viet Nam, which does not preclude the potential future discovery of sites along previous lowland areas and coastlines that are currently submerged.

The skeletal and dental remains of 96 individuals, representing the Da But period, derive from the single cemetery site Con Co Ngua (Table 1). The following account of this site is based on the unpublished site report prepared by Bui Vinh (1980). Con Co Ngua lies in Ha Trung District, Thanh Hoa Province, some 30 $\mathrm{km}$ from the present coast, approximately $3 \mathrm{~km}$ north of the Ma River, at $20^{\circ} \mathrm{N}$, $105^{\circ} 45^{\prime} \mathrm{E}$ (Fig. 1). Con Co Ngua is situated on a low mound within a small valley at the foot of encircling hills. These hills range from 50 to $350 \mathrm{~m}$ above sea level. It can thus be seen as situated within a transitional plains-upland region. However, it is still low enough to be constantly flooded during the rainy season. The occupants would have had access to riverine, estuarine, coastal, and dense subtropical forest resources within close proximity to the site.

A $228.5 \mathrm{~m}^{2}$ excavation comprising two adjacent pits on and by the mound was 
Table i. Summary of Sites Sampled in This Study

\begin{tabular}{lllll}
\hline PERIOD & \multicolumn{1}{c}{ SITE } & REGION & INDIVIDUALS & \multicolumn{1}{c}{ DATE (YEARS B.P.) $^{\mathrm{I}}$} \\
\hline Da But & Con Co Ngua & Ma River & 96 & $\sim 6000$ \\
Metal & Vinh Quang & Red River & 13 & 2200 to 1700 \\
& Min Duc & Red River & 5 & 2200 to 1700 \\
& Duong Co & Red River & 1 & 2200 to 1700 \\
& Dinh Chang & Red River & 8 & 2200 to 1700 \\
& Doi Son & Red River & 7 & 2200 to 1700 \\
& Chau Son & Red River & 1 & $2285 \pm 45$ \\
& Dong Xa & Red River & 1 & 2200 to 1700 \\
& Quy Chu & Ma River & 4 & $2450 \pm 45,2520 \pm 55^{2}$ \\
& Quy Chu & Ma River & 16 & 3300 to 2500 \\
& Nui Nap & Ma River & 2 & 3000 to 2500 \\
& Nui Nap & Ma River & 2 & 2400 to 2000 \\
& Nui Nap & Ma River & 30 & 3000 to 2800 \\
& Thieu Duong & Ma River & 1 & 2200 to 1700 \\
\hline
\end{tabular}

Notes: 1 . Individuals represented by skeletal/dental remains. 2. Radiocarbon date.

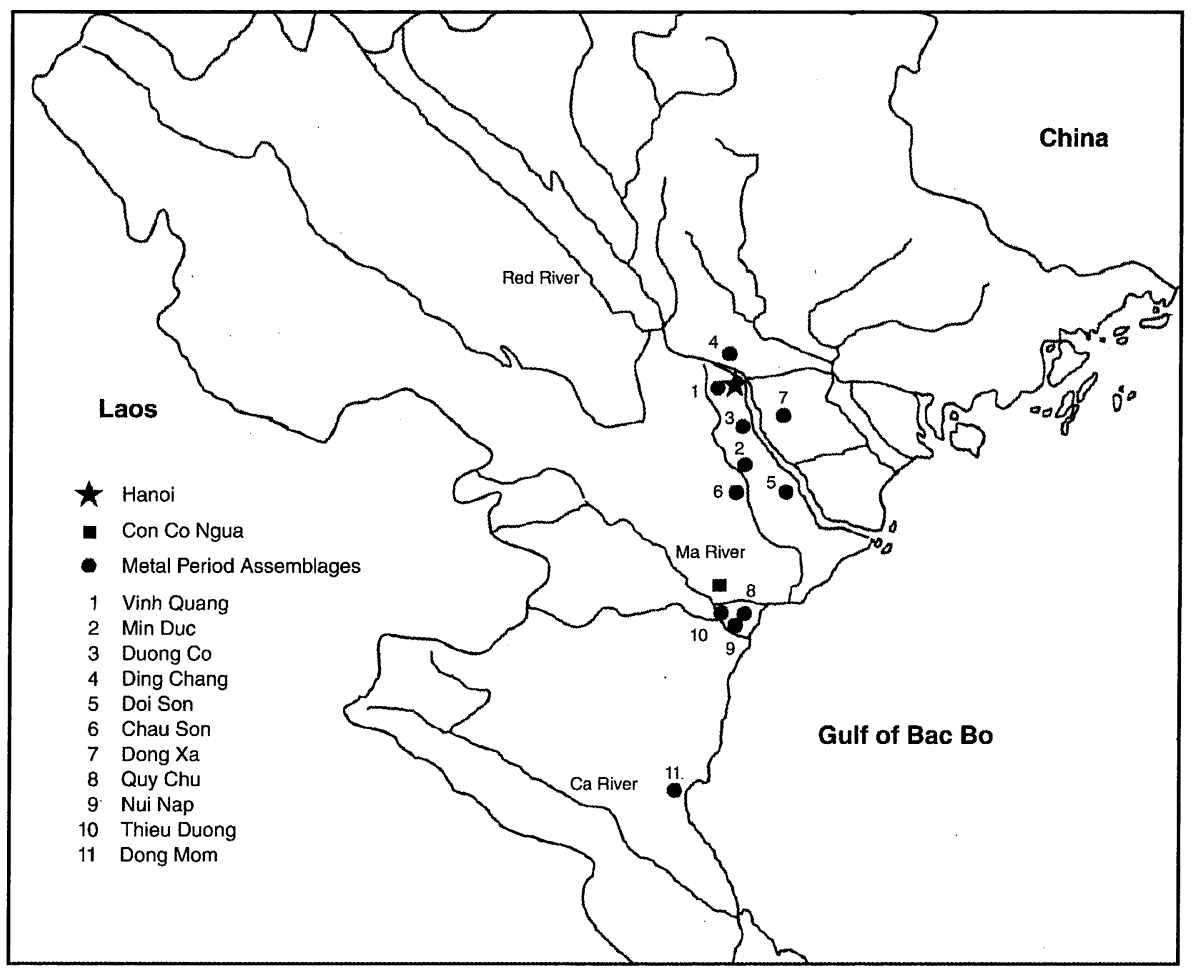

Fig. 1. Northern Viet Nam: Sites with biological remains examined in this study (from Oxenham et al. 2005). 
carried out in 1979. In the majority of cases, individuals were buried tightly flexed, both the upper and lower limbs, in a type of squatting or seated fetal position. Graves were generally only earthen pits with no sign of any other lining or covering material. However, at least five single graves were associated with a stone marker on top of or beside the grave. The majority of burials for which an orientation could be discerned were facing east or northeast. Signs of what appears to be ochre were spread over at least one clustered burial, while ochre solidified into the shape of a gourd was found in two separate graves. In three cases, stag horns were found buried beside individuals. It was not uncommon to find in the graves bones of various vertebrates such as buffalo, pig, turtle, and fish, as well as shells of invertebrates such as oysters, mussels, and snails. Material cultural objects recovered from Con Co Ngua include numerous grinding stones, ground axes, and mat-impressed pottery fragments. I also recovered a worked bone artifact, possibly an ornament, from among the remains of one curated individual from the site.

While the stratigraphy of Con Co Ngua is not clear, the burials are essentially found within midden material containing a high concentration of freshwater molluscs and saltwater oysters and mussels. A sterile capping layer including blue-grey clay, spread throughout the valley to a depth of $0.5-1.5 \mathrm{~m}$, has been interpreted as representing a major flood.

The two excavated pits are believed to be temporally discontinuous, although it is not clear what period of time separates them. The 28 burials from Pit 1 are single or double burials, while the 78 burials from Pit 2 form mostly clustered inhumations. The skeletal remains of 96 individuals were available for examination. Of these, 25 were from Pit 1, 64 from Pit 2, and 7 individuals who could not be assigned confidently to a specific pit.

While only the basal phase of Con Co Ngua contains human remains, the upper level of the site, dated by way of material culture associations to around 5500 years B.P., shows an absence of molluscs and salt-marsh plants, suggesting the coast had started to prograde by this stage. The material culture also changes, with the first appearance of fishing net sinkers, spinning whorls, stone awls, stone chisels, and technological changes in stone axes. Moreover, there is a large increase in the frequency of polished and curved stone artifacts that have been interpreted as hoes. There is also an increase in the number of domesticated buffalo and pig remains. The final phase of the Da But period (the Go Trung phase), beginning around 5000 years B.P. and not represented at Con Co Ngua, shows technological changes with respect to pottery and stone artifacts. Settlements are seen to spread along the coast, and the development of sea travel and sea fishing has been suggested (Bui Vinh 1991, 1996). This would indicate changes from a coastally oriented economy to a marine-based one in the later phase of the Da But period.

\section{THE METAL PERIOD}

The Metal period in this study is represented by 11 sites, the vast majority of which are located either within the Red River delta region or just south of the delta in the Ma River region (see Table 1 and Fig. 1). Much of the skeletal material from these sites is dated to between 2500 and 1700 years B.P. This places the majority of the skeletal and dental sample within the periods of the Dong Son 
proper and early Han encroachments into the region. Very few radiometric dates exist for these sites, with the majority being dated by way of material culture associations.

The earliest evidence for metal in the Red River delta region appears in late Phung Nguyen culture contexts. These sites are situated on relatively raised areas on the edge of the Red River delta. The Phung Nguyen culture, believed to have endured from 4000 to 3500 years B.P., is notable for its rich and technologically sophisticated array of stone jewelry. Following this period is a succession of phases in the Red River region, mirrored by analogous culture phases in the $\mathrm{Ma}$ and $\mathrm{Ca}$ River regions, culminating in the Dong Son, dating from 2500 years B.P. until Han domination in the first centuries of the first millennium A.D.

Higham (1989:30) has described the Vietnamese Dong Son as one of several Southeast Asian examples demonstrating social differentiation and a move "from village autonomy towards centralised chiefdoms." Apart from the diverse range and technological sophistication of material culture objects, there is evidence for marked craft specialization, a complex ritual life, maritime trade, sophisticated military skills and equipment, and the development of an aristocratic and centralized elite based on agricultural surpluses (Higham 1996:134). Evidence for the latter proposition may be testable through an examination of the skeletal remains of the people themselves.

Han chronicles of the people and region are available to supplement the archaeological picture. The region, encompassing the vast majority of Metal period sites included in this study, moved in and out of direct Han administrative control from the late third century B.C. (De Crespigny 1990). Schafer (1967) suggests that initial military conquest and control of the region likely had a minimal cultural and social impact. It was not until concerted Chinese migration into the region occurred in the first century A.D. that significant sociocultural effects were seen. Even with migration and the vagaries of central Chinese control of the regionand during periods of independence from China-De Crespigny (1996) argues that Chinese culture was maintained by the emigrants.

Holmgren (1980) points out that early Chinese officials in northern Viet Nam have traditionally been praised in the histories for their efforts to "civilize" these people, citing the introduction of metal agricultural implements and agricultural techniques such as land reclamation and education. The point regarding agricultural improvements is important in suggesting that, prior to the intensification in Chinese colonizing efforts, the region lacked an agricultural subsistence economy. While Chinese historical sources tell of local swidden agriculture, there is no mention of any Vietnamese communities having an agricultural economic focus. It would also appear that the introduction of intensive agricultural techniques and practices was essentially about Chinese exploitation of the region as a rice basket.

Schafer (1967) taps into a wealth of Tang dynasty material, much of it written by Chinese court officials banished to the south, giving some insight into issues of health and disease. A recurrent theme is the deadly disease-carrying miasmas or fogs of Nam Viet. Many of these banished officials are recorded to have died after only short periods of time in the south. Disease was such a problem in Nam Viet that military reprisals against local rebellions in the region, during the Tang dynasty at least, had been canceled in the face of the predicted effects of malaria 
on the Chinese army. One Tang insurgent, Huang Chao, was reported to have lost up to 40 percent of his army to disease during a campaign against Canton (Guangzhou), a city near present-day Hong Kong.

Interestingly, however, historical population statistics attest to a relative absence of the effects of malaria in both the Canton and Hanoi delta regions (Schafer 1967). The higher ground and areas back from the coast do not seem to have been so lucky, however. Lu and Needham (1993) note that the Chinese had some knowledge of malaria and were differentiating between the tertian (fever occurring every third day) and quartan forms by the sixth century B.C.

The Chinese of the Tang also recorded indigenous perceptions and explanations for disease. The most striking conception of the causes of many diseases was black sorcery, or $\mathrm{Ku}$. $\mathrm{Ku}$ is still practiced in present-day Guang Xi Province and was known to the Chinese from Zhou dynasty ( 1000-257 B.C.) times (Schafer 1967). While $\mathrm{Ku}$ diseases were often seen as the result of sorcerous activities, they could also be caused by the ubiquitous miasmas. It has also been suggested that numerous oedematous conditions attributed to $\mathrm{Ku}$ were in fact caused by intestinal parasites. Another specific disease known to the Chinese in Nam Viet for a considerable period of time was beriberi, or leg vapors (athiaminosis). Lu and Needham (1993) suggest that the first Chinese reference to beriberi occurs in 584 B.C. A range of treatments for this condition was prescribed by Chinese pharmacologists that included quince, gourd, almonds, and betel nut (Schafer 1967). The use of betel nut has been archaeologically demonstrated for Bronze Age Viet Nam (Oxenham et al. 2002). It is not clear what contribution indigenous knowledge had in developing these cures.

The severe gastrointestinal and fever symptoms of cholera were also known to the Chinese of the region (Schafer 1967). It has been suggested that cholera was being described in Chinese texts by around 200 B.C. (Lu and Needham 1993). A vast, diverse, and at times bizarre range of treatments was prescribed for the condition (Schafer 1967). Typhus is another disease that was well known and, in fact, a Han dynasty treatise was written on the condition. No doubt the more generalized Chinese accounts of disease in Nam Viet, from very early on, drew on an extensive indigenous experience of all manner of colds, fevers, dysentery, skin lesions, parasitic infections, and so forth.

\section{ASSESSING HEALTH AND BEHAVIOR}

One of the most important issues encountered in studies of human palaeohealth is how representative the skeletal sample is of the once living population. Taphonomic and sampling considerations are as crucial to interpretations of human biology as the material culture. At a minimum, an assessment of the demographic profile of a skeletal assemblage is required to determine departures from expectations. Both of the samples examined in this paper depart from the expected demographic pattern in that subadults are very poorly represented. While this does not negate the findings concerning their health, it must be borne in mind that for the most part, only an adult portion of these past communities is being examined.

A number of authors (e.g., Harpending 1990; Ortner 1992; Wood et al. 1992) have highlighted potentially serious issues in the way skeletal samples are used 
to interpret palaeohealth. While the concerns of these researchers have been specifically (e.g., Cohen 1997; Goodman 1993) and generally (e.g., Steckel and Rose 2002) addressed, a consensus approach and view of what has come to be termed the "osteological paradox" is yet to develop. However, extensive reviews of the bioarchaeological literature (e.g., Larsen 1997) and recent large-scale assessments of Palaeohealth (e.g., Steckel and Rose 2002) suggest that the employment of a range of health markers produces an assessment of health robust to such problems as demographic nonstationarity, heterogeneity of risk (morbidity and mortality), and selective mortality.

In assessing the relative health of the $\mathrm{Da}$ But and Metal period samples, a selection of skeletal and dental markers of both health and behavior commonly used by bioarchaeologists (see Larsen 1997; Steckel and Rose 2002) has been chosen. Linear enamel hypoplasia (caused by disruptions to the formation of enamel during tooth development) and cribra orbitalia (characterized by resorption of cortical bone and/or proliferation of bone in the roof of the orbit of the eye) were recorded as indicators of general physiological or metabolic disruption in childhood. The etiology of both conditions is complex, but it includes environmental and behavioral (e.g., diet, living conditions) variables. A range of commonly recorded dental conditions from carious lesions to alterations in the dentition caused by extramasticatory use of the teeth has been recorded in the secondary or adult dentition. This provides a general oral health profile of each sample as well as providing information on potential specific behaviors (e.g., diet and use of the teeth as tools). The evidence for trauma (acute injury) and infection (specific and nonspecific chronic disease) affecting children and adults is also discussed in order to develop a reasonably comprehensive assessment of the health and behavior of these samples.

\section{ASSEMBLAGES}

The archaeological, environmental, and geographic context of the sampled sites has been reviewed. The Da But period sample comprises skeletal and dental remains representing 96 individuals (Table 2) from a single cemetery site in present day Thanh Hoa Province, dated by way of material cultural associations to between 6000 and 5500 years B.P. The Metal period is also represented by 96 individuals (see Table 2) from 11 sites, the vast majority of which are located either within the Red River delta region or just south of the delta in the Ma River region. Much of the skeletal material from these sites is dated to between 2500 and 1700 years B.P., placing them within the periods of the Dong Son proper and early Han encroachments into the region. Comparisons are made with a number of contemporaneous assemblages from Thailand, and these are summarized in Table 3.

\section{RECORDING PROTOCOLS}

The skeletal and dental signifiers of health, disease, and behavior selected for analysis in this study have been introduced in the previous section discussing the definition and assessment of health. The presence of all linear enamel hypoplastic (LEH) defects corresponding to the DDE index type 4 (Federation Dentaire In- 
Table 2. Da But and Metal Period Age-at-Death and Sex Distribution

\begin{tabular}{|c|c|c|c|c|c|c|}
\hline \multirow[b]{2}{*}{ AGE CLASS } & \multicolumn{3}{|c|}{ DA BUT SAMPLE } & \multicolumn{3}{|c|}{ METAL PERIOD SAMPLE } \\
\hline & MALES & FEMALES & TOTAL $(\%)$ & MALES & FEMALES & TOTAL (\%) \\
\hline $0-11$ months & na & na & $1(1.0)$ & na & na & $2(2.1)$ \\
\hline $1-14$ years & na & na & $6(6.3)$ & na & na & $11(11.5)$ \\
\hline $15-19$ years & 3 & 1 & $9(9.4)$ & 1 & 5 & $9(9.4)$ \\
\hline $20-29$ years & 5 & 6 & $14(14.6)$ & 11 & 9 & $27(28.1)$ \\
\hline $30-39$ years & 14 & 7 & $22(22.9)$ & 6 & 11 & $17(17.7)$ \\
\hline $40-49$ years & 4 & 9 & $14(14.6)$ & 3 & 3 & $9(9.4)$ \\
\hline $50+$ years & 11 & 7 & $18(18.8)$ & 5 & 1 & $7(7.3)$ \\
\hline Indeterminate $^{1}$ & 6 & 1 & $12(12.5)$ & 2 & 6 & $13(13.5)$ \\
\hline Indeterminate ${ }^{2}$ & 0 & 0 & $0(0.0)$ & 0 & 0 & $1(1.0)$ \\
\hline Total n & 43 & 31 & 96 & 28 & 35 & 96 \\
\hline
\end{tabular}

Notes: Table adapted from Oxenham et al. (2005). 1. Indeterminate; adult but could not be assigned to an age category. 2. Indeterminate; too fragmentary to assign as adult or subadult.

Table 3. Skeletal Assemblages Referred to in This Paper

\begin{tabular}{llll}
\hline ASSEMBlage & DATE (YeARS B.P.) & PHYSiCAl LOCATION & CHIEF SUBSistenCE \\
\hline Viet Nam & & & \\
Viet Nam Da But & $6,000-5,500$ & estuary/river & $\mathrm{Fa} / \mathrm{t}$ \\
Viet Nam Ma, Ca Rivers & $2,500-1,700$ & inland/river & $\mathrm{M}$ \\
Viet Nam Red River & $2,200-1,700$ & estuary/river & $\mathrm{M}$ \\
Thailand & & & $\mathrm{Fa} / \mathrm{t}(\mathrm{A}$ ?) \\
Khok Phanom Di & $4,000-3,500$ & estuary/coast & $\mathrm{M}$ \\
Early Non Nok Tha & $4,800-3,400$ & inland/river & $\mathrm{M}$ \\
Early Ban Chiang & $4,100-2,900$ & inland/river & $\mathrm{M}$ \\
Late Non Nok Tha & $3,400-2,200$ & inland/river & $\mathrm{A}(\mathrm{Fa})$ \\
Nong Nor & $3,100-2,700$ & coast/river & $\mathrm{M}$ \\
Ban Lum Khao & $3,000-2,500$ & inland/river & $\mathrm{M}$ \\
Late Ban Chiang & $2,900-1,800$ & inland/river & $\mathrm{A}(\mathrm{F})$ \\
Ban Na Di & $2,600-2,400$ & inland/river & $\mathrm{A} / \mathrm{H}$ \\
Noen U-Loke & $2,300-1,700$ & inland/river & \\
\hline
\end{tabular}

Table adapted from Oxenham et al. (2006). Subsistence abbreviations: $F=$ foraging; $M=F o r a g i n g$ and Agriculture Mix; $\mathrm{A}=$ Agriculture; $\mathrm{H}=$ Cattle Herding; $\mathrm{a}=$ aquatic; $\mathrm{t}=$ terrestrial. Subsistence abbreviations in parentheses indicate secondary importance.

ternational 1982) on the labial face of the permanent left maxillary and/or mandibular canines, or their antimere substitutions, were recorded. Maximally, an individual for the purposes of LEH assessment is defined by the presence two canines (a maxillary and a mandibular) and minimally by one canine (maxillary or mandibular). Heavily worn teeth exhibiting $>50$ percent loss of estimated crown height were excluded from analysis. LEH severity followed Duray (1996), although only severity categories 1 and 2 are reported here. The advantage of using the maxillary and mandibular canines in this study is the much greater preservation, compared to incisors, in both the Da But period and Metal period samples. 
The window of sensitivity to stress in the developmental period of the canines is between 1.5 and 4.5 years.

For cribra orbitalia (CO), all cranial material with at least the preservation of the anterolateral and anteromedial portions of the orbital roof of at least one orbit was assessed. CO is defined and scored as either open or closed, where open includes perforations of the outer table of the orbital roof and may indicate incompletely remodeled $\mathrm{CO}$ or lesions active at the time of death. Closed $\mathrm{CO}$ refers to what is believed to be highly remodeled (inactive) $\mathrm{CO}$, where perforations of the outer table of the orbital roof can no longer be observed. This form is generally easily recognizable by the distinctive wormlike patterning of the outer table of the orbital roof. Closed CO is scored as a separate category, as commonly used recording schemes do not have a provision for scoring the highly remodeled form of $\mathrm{CO}$ as present.

Recording protocols for oral traits and traumatic and infectious lesions are detailed in Oxenham et al. (2001, 2002, 2005), and only permanent teeth and alveoli (tooth sockets) were assessed. Of the numerous oral traits available, four were selected that are broadly sensitive to both behavior and health: carious lesions, antemortem tooth loss, alveolar defects of pulpal origin, and extramasticatory wear facets. Carious lesion frequencies have not been corrected, following arguments forwarded in Hillson (2001). The terms "abscess" and "granuloma" (see discussion of these terms in Dias and Tayles 1997) are not employed due to problems in identifying the relative active or benign status of these lesions in dry bone. The assumption-free term "alveolar defect of pulpal origin" has been adopted in this study for what are commonly termed periapical abscesses. The oral data are presented by individual and tooth or alveolus count. For oral health purposes, an individual is defined as one or more dental structures attributable to only a single specimen and could maximally include a complete maxilla and mandible or minimally a single alveolus/tooth (although the minimum was not invoked in this study).

\section{RESULTS \\ General Physiological Well-Being}

A dental (linear enamel hypoplasia, LEH) indicator and a skeletal (cribra orbitalia, $\mathrm{CO}$ ) indicator of physiological and metabolic disruption in the childhood of subsequently sampled adult skeletal material were examined. The range of causes potentially associated with the development of physiological or metabolic disruption includes poor diet, periods of starvation, parasite loads, genetic disorders (e.g., thalassemia), effects of disease in general, and anemia.

While LEH data was collected for the mandibular and maxillary canines separately, the results are combined here and reported by individual only (Table 4). Of the $53 \mathrm{Da}$ But period individuals with assessable maxillary and/or mandibular canines, 71.7 percent displayed LEH. A greater proportion of females display LEH (81.3 percent) than males (63.0 percent), albeit not a statistically significant difference. While the oldest age class has the lowest proportion of individuals with $\mathrm{LEH}$, there is no statistically significant heterogeneity by age class. 
Table 4. Frequency of Canine LEH by Individual

\begin{tabular}{|c|c|c|c|c|c|c|}
\hline \multirow[b]{2}{*}{ AGE CLASS } & \multicolumn{3}{|c|}{ PERIOD: DA BUT } & \multicolumn{3}{|c|}{ PERIOD: METAL } \\
\hline & MALE & FEMALE & TOTAL & MALE & FEMALE & TOTAL \\
\hline$<30$ & $4 / 5(80)$ & $4 / 4(100)$ & $15 / 18(83)$ & $6 / 7(86)$ & $6 / 10(60)$ & $18 / 26(69)$ \\
\hline $30-39$ & $6 / 9(67)$ & $3 / 3(100)$ & $9 / 12(75)$ & $5 / 5(100)$ & $8 / 10(80)$ & $13 / 15(87)$ \\
\hline $40+$ & $7 / 13(54)$ & $6 / 9(67)$ & $14 / 23(61)$ & $5 / 8(63)$ & $1 / 3(33)$ & $6 / 12(50)$ \\
\hline Indet. & - & - & - & $0 / 0(0)$ & $0 / 0(0)$ & $0 / 2(0)$ \\
\hline Total & $17 / 27(63)$ & $13 / 16(81)$ & $38 / 53(72)$ & $16 / 20(80)$ & $15 / 23(65)$ & $37 / 55(67)$ \\
\hline
\end{tabular}

Notes: Severe and moderate (grades 1 and 2) LEH only. Figures given as numerator/denominator (percentage). Indet. $=$ indeterminate age at death and/or sex.

Of the 55 Metal period individuals with assessable maxillary and/or mandibular canines, 67.3 percent displayed LEH. A greater proportion of males ( 80.0 percent) had LEH than females (65.2 percent), albeit not to a statistically significant degree. Again, while there appears to be a lower representation of LEH in the oldest age class, the null hypothesis of age class homogeneity for LEH frequency is not rejected.

The higher frequency of LEH in the Da But period sample is not statistically significantly greater than that for the Metal period sample $\left(\chi^{2} 0.05, p \leq 0.1\right)$. Further, the mean number of LEH events per individual in the Metal period sample $(\mathrm{n}=106$ canines and 55 individuals, mean 2.9 ) is not statistically significantly larger $(\mathrm{t} 1.38, \mathrm{p} \leq 0.2)$ than the mean for the Da But period sample ( $\mathrm{n}=90$ canines and 53 individuals, mean 2.4).

Some 81 percent of the Da But sample displayed open and/or closed cribra orbitalia (Table 5). Only one individual was less than 15 years old-a 9-year-old child with extensive confluent lesions. A slightly greater but not statistically significant frequency of $\mathrm{CO}$ is seen in males (83.3 percent) compared to females (73.7 percent). The frequency of $\mathrm{CO}$ is constant across each of the three age classes. Of the affected sample, 34.0 percent displayed open CO. When only those cases of open $\mathrm{CO}$ are examined, 23.3 percent of the males and 21.1 percent of femalesor a total of 27.6 percent of the assessable sample-was affected. There is a clear tendency for open $\mathrm{CO}$ to occur in the youngest age class, and this heterogeneity is statistically significant.

In the Metal period sample, the frequency of all manifestations of $\mathrm{CO}$ is 73.2 percent-72.7 percent for males and 72.0 percent for females. Included in this sample are three subadults ( $<15$ years), of which two display CO. Of the affected sample, 41.5 percent displayed open $\mathrm{CO}$. When only those cases of open $\mathrm{CO}$ are considered, 27.3 percent of the males and 24.0 percent of females-or a total of 30.4 percent of the assessable sample-was affected. As with the Da But period sample, most of the open $\mathrm{CO}$ in the Metal period sample occurs in the youngest age class, and this is statistically significant. Regardless of how CO is scored, there are no statistically significant differences in frequency between the $\mathrm{Da}$ But and Metal period samples (combined open and closed $\mathrm{CO}, \chi^{2} 0.13, \mathrm{p} \leq 0.1$; open $\left.\mathrm{CO}, \chi^{2} 0.06, \mathrm{p} \leq 0.1\right)$. 
Table 5. Frequency of Cribra Orbitalia by Individual

PERIOD: DA BUT

\begin{tabular}{|c|c|c|c|c|c|c|}
\hline \multirow[b]{2}{*}{ AGE CLASS } & \multicolumn{2}{|l|}{ MALE } & \multicolumn{2}{|c|}{ FEMALE } & \multicolumn{2}{|c|}{ TOTAL } \\
\hline & OPEN \& CLOSED & OPEN & OPEN \& CLOSED & OPEN & OPEN \& CLOSED & OPEN \\
\hline$<30$ & $2 / 2(100)$ & $1 / 2(50)$ & $3 / 4(75)$ & $2 / 4(50)$ & $11 / 12(92)$ & $7 / 12(58)$ \\
\hline $30-39$ & $11 / 13(85)$ & $3 / 13(23)$ & $2 / 4(50)$ & $0 / 4(0)$ & $13 / 17(76)$ & $3 / 17(18)$ \\
\hline $40+$ & $8 / 11(73)$ & $1 / 11(9)$ & $9 / 11(82)$ & $2 / 11(18)$ & $18 / 23(78)$ & $4 / 23(17)$ \\
\hline Indet. & $4 / 4(100)$ & $2 / 4(50)$ & $0 / 0(0)$ & $0 / 0(0)$ & $5 / 6(83)$ & $2 / 6(33)$ \\
\hline Total & $25 / 30(83)$ & $7 / 30(23)$ & $14 / 19(74)$ & $4 / 19(21)$ & $47 / 58(81)$ & $16 / 58(28)$ \\
\hline
\end{tabular}

Age open \& closed $\chi^{2} 1.213, \mathrm{p} \leq 1 \quad$ Age open $\chi^{2}$ 7.823, $\mathbf{p} \leq \mathbf{0 . 0 2}$ Sex $^{*} \chi^{2} 0.667, \mathrm{p} \leq 0.5$

PERIOD: METAL

\begin{tabular}{|c|c|c|c|c|c|c|}
\hline \multirow[b]{2}{*}{ AGE CLASS } & \multicolumn{2}{|l|}{ MALE } & \multicolumn{2}{|c|}{ FEMALE } & \multicolumn{2}{|c|}{ TOTAL } \\
\hline & OPEN \& CLOSED & OPEN & OPEN \& CLOSED & OPEN & OPEN \& CLOSED & OPEN \\
\hline$<30$ & $7 / 8(88)$ & $4 / 8(50)$ & $7 / 11(64)$ & $4 / 11(36)$ & $20 / 26(77)$ & $12 / 26(46)$ \\
\hline $30-39$ & $2 / 5(40)$ & $1 / 5(20)$ & $7 / 8(88)$ & $0 / 8(0)$ & $9 / 13(69)$ & $1 / 13(8)$ \\
\hline $40+$ & $6 / 8(75)$ & $1 / 8(13)$ & $1 / 3(33)$ & $0 / 3(0)$ & $7 / 11(64)$ & $1 / 11(9)$ \\
\hline Indet. & $1 / 1(100)$ & $0 / 1(0)$ & $3 / 3(100)$ & $2 / 3(67)$ & $5 / 6(83)$ & $3 / 6(50)$ \\
\hline Total & $16 / 22(73)$ & $6 / 22(27)$ & $18 / 25(72)$ & $6 / 25(24)$ & $41 / 56(73)$ & $17 / 56(30)$ \\
\hline \multicolumn{3}{|c|}{ Age open $\&$ closed $\chi^{2} 0.744, p \leq 1$} & \multicolumn{2}{|c|}{ Age open $\chi^{2} 8.861, \mathbf{p} \leq \mathbf{0 . 0 2}$} & \multicolumn{2}{|c|}{$\operatorname{Sex}^{*} \chi^{2} 0.0003, \mathrm{p} \leq 1$} \\
\hline
\end{tabular}

Figures given as numerator/denominator (percentage). Indet. = indeterminate age at death and/or sex.

* Open and closed cribra orbitalia.

\section{Oral Health}

Carious lesions, antemortem tooth loss, and alveolar defects of pulpal origin are often used in the generation of oral health profiles. Not only are these pathological conditions useful in assessing oral health, they have a complex etiology that includes aspects of human behavior, particularly in terms of diet, food preparation techniques, and extra oral activities to a degree. More specific extramasticatory behaviors can be assessed by an examination of alterations in the dentition caused by materials usually foreign to the oral cavity and indicative of a diverse range of activities: fiber and skin processing to lithic artifact retouching by way of the teeth, for instance.

Carious Lesions - Unless otherwise noted, results are reported by individual, with tooth or alveolus counts reported in parentheses. The frequency of carious lesions was not significantly different, regardless of reporting method, between periods with 13.8 percent of individuals (1.5 percent teeth) having lesions in the Da But sample and 20.8 percent of individuals (2.3 percent teeth) in the Metal period sample (Table 6). Tests for homogeneity of lesion frequency across age classes in the $\mathrm{Da}$ But sample indicated that the distribution is not even, with older individuals displaying more lesions. The vast majority of lesions manifested in the molars, with only 7.1 percent of $\mathrm{Da}$ But lesions affecting the anterior (canines and incisors) dentition. With respect to sex, there were no significant differences in le- 
Table 6. Frequency of Carious Lesions

PERIOD: DA BUT

\begin{tabular}{|c|c|c|c|c|c|c|}
\hline \multirow[b]{2}{*}{ AGE CLASS } & \multicolumn{2}{|c|}{ MALE } & \multicolumn{2}{|c|}{ FEMALE } & \multicolumn{2}{|c|}{ TOTAL } \\
\hline & INDIVIDUAL & TоOтH & INDIVIDUAL & TOOTH & INDIVIDUAL & TOOTH \\
\hline$<30$ & $0 / 6(0)$ & $0 / 73(0)$ & $1 / 5(20)$ & $2 / 60(3.3)$ & $1 / 25(4)$ & $2 / 289(0.7)$ \\
\hline $30-39$ & $1 / 13(7.7)$ & $1 / 187(0.5)$ & $0 / 7(0)$ & $0 / 71(0)$ & $1 / 21(4.8)$ & $1 / 262(0.4)$ \\
\hline $40+$ & $4 / 15(26.7)$ & $6 / 181(3.3)$ & $5 / 16(31)$ & $5 / 202(2.5)$ & $9 / 32(28.1)$ & $11 / 396(2.8)$ \\
\hline Indet. & $0 / 2(0)$ & $0 / 4(0)$ & $0 / 0(0)$ & $0 / 0(0)$ & $0 / 2(0)$ & $0 / 4(0)$ \\
\hline Total & $5 / 36(13.9)$ & $7 / 445(1.6)$ & $6 / 28(21.4)$ & $7 / 333(2.1)$ & $11 / 80(13.8)$ & $14 / 951(1.5)$ \\
\hline \multicolumn{3}{|c|}{$\begin{array}{l}\text { Age individual } \chi^{2} 8.813, \mathbf{p} \leq \mathbf{0 . 0 1} \\
\text { Age tooth } \chi^{2} 7.981, \mathbf{p} \leq \mathbf{0 . 0 2}\end{array}$} & \multicolumn{4}{|c|}{ Sex individual $\chi^{2} 0.441, \mathrm{p} \leq 1$} \\
\hline \multicolumn{7}{|c|}{ PERIOD: METAL } \\
\hline & \multicolumn{2}{|c|}{ MALE } & \multicolumn{2}{|c|}{ FEMALE } & \multicolumn{2}{|c|}{ TOTAL } \\
\hline AGE CLASS & INDIVIDUAL & TоOтн & INDIVIDUAL & TOOTH & INDIVIDUAL & ТООТн \\
\hline$<30$ & $4 / 10(40)$ & $5 / 207(2.4)$ & $6 / 12(50)$ & $9 / 209(4.3)$ & $11 / 40(27.5)$ & $16 / 565(2.8)$ \\
\hline $30-39$ & $0 / 6(0)$ & $0 / 115(0)$ & $3 / 10(30)$ & $6 / 201(3)$ & $3 / 16(18.8)$ & $6 / 316(1.9)$ \\
\hline $40+$ & $1 / 8(12.5)$ & $2 / 181(1.1)$ & $1 / 4(25)$ & $2 / 51(3.9)$ & $2 / 16(12.5)$ & $4 / 254(1.6)$ \\
\hline Indet. & $0 / 2(0)$ & $0 / 3(0)$ & $0 / 1(0)$ & $0 / 1(0)$ & $0 / 5(0)$ & $0 / 17(0)$ \\
\hline Total & $5 / 26(19.2)$ & $7 / 506(1.4)$ & $10 / 27(37)$ & $17 / 462(3.7)$ & $16 / 77(20.8)$ & $26 / 1152(2.3)$ \\
\hline \multirow{2}{*}{\multicolumn{3}{|c|}{ Age individual $\chi^{2} 1.631, \mathrm{p} \leq 1$}} & \multicolumn{4}{|c|}{ Sex individual $\chi^{2} 1.165, \mathrm{p} \leq 1$} \\
\hline & & & \multicolumn{4}{|c|}{ Sex tooth $\chi^{2} \mathbf{5 . 0 0 7}, \mathbf{p} \leq \mathbf{0 . 0 5}$} \\
\hline
\end{tabular}

Figures given as numerator/denominator (percentage). Indet. $=$ indeterminate age at death and/or sex.

sion distribution, with 13.9 percent of Da But males (1.6 percent teeth) compared to 21.4 percent of females (2.1 percent teeth) having lesions. With regard to lesion location, 71.4 percent of all lesions in the Da But sample were located in the maxillary dentition, and lesions were distributed as follows: occlusal (35.7 percent), mesial (21.4 percent), distal (28.6 percent), lingual (7.1 percent), buccal (0 percent), unknown origin (7.1 percent). Further, 35.7 percent of all Da But period lesions were located on the root or cervix of the tooth.

In the Metal period sample, the younger age classes had a higher frequency of lesions, although the hypothesis that the lesion frequency is homogenous across age classes was not rejected, either by individual or tooth count. Very few Metal period carious lesions (15.4 percent of all lesions) manifested in the anterior dentition. More Metal period female individuals had lesions (37 percent; 3.7 percent teeth) than males (19.2 percent; 1.4 percent teeth), and this difference was significant when assessed by tooth count. In terms of location, 57.7 percent of all lesions in the Metal period sample were located in the maxillary dentition, and lesions were distributed as follows: occlusal (53.8 percent), mesial (7.7 percent), distal (34.6 percent), lingual (0 percent), buccal (3.8 percent). Additionally, 26.9 percent of all Metal period lesions were located on the root or cervix of the tooth.

Antemortem Tooth Loss - Antemortem tooth loss (AMTL) was greater by individual (29.7 percent) and statistically significantly greater by alveolus count (4.8 per- 
Table 7. Frequency of Antemortem Tooth Loss

PERIOD: DA BUT

\begin{tabular}{|c|c|c|c|c|c|c|}
\hline \multirow[b]{2}{*}{ AGE CLASS } & \multicolumn{2}{|c|}{ MALE } & \multicolumn{2}{|c|}{ FEMALE } & \multicolumn{2}{|c|}{ TOTAL } \\
\hline & INDIVIDUAL & ALVEOLUS & INDIVIDUAL & ALEVOLUS & INDIVIDUAL & ALVEOLUS \\
\hline$<30$ & $1 / 6(16.7)$ & $1 / 106(0.9)$ & $1 / 5(20)$ & $1 / 90(1.1)$ & $3 / 23(13)$ & $3 / 377(0.8)$ \\
\hline $30-39$ & $2 / 13(15.4)$ & $2 / 296(0.7)$ & $1 / 6(16.7)$ & $3 / 107(2.8)$ & $3 / 20(15)$ & $5 / 408(1.2)$ \\
\hline $40+$ & $8 / 14(57.1)$ & $30 / 286(10.5)$ & $8 / 16(50)$ & $31 / 343(9)$ & $16 / 31(51.6)$ & $61 / 645(9.5)$ \\
\hline Indet. & $0 / 0(0)$ & $0 / 0(0)$ & $0 / 0(0)$ & $0 / 0(0)$ & $0 / 0(0)$ & $0 / 0(0)$ \\
\hline Total & $11 / 33(33.3)$ & $33 / 688(4.8)$ & $10 / 27(37)$ & $35 / 540(6.5)$ & $22 / 74(29.7)$ & $69 / 1430(4.8)$ \\
\hline \multirow{2}{*}{\multicolumn{3}{|c|}{$\begin{array}{l}\text { Age individual } \chi^{2} 12.248, \mathrm{p} \leq 0.01 \\
\text { Age alveolus } \chi^{2} 54.978, \mathrm{p} \leq \mathbf{0 . 0 0 1}\end{array}$}} & \multicolumn{4}{|c|}{ Sex individual $\chi^{2} 0.043, \mathrm{p} \leq 1$} \\
\hline & & & Sex alveolus & $\chi^{2} 1.467, \mathrm{p} \leq$ & & \\
\hline \multicolumn{7}{|c|}{ PERIOD: METAL } \\
\hline & \multicolumn{2}{|c|}{ MALE } & \multicolumn{2}{|c|}{ FEMALE } & \multicolumn{2}{|c|}{ TOTAL } \\
\hline AGE CLASS & INDIVIDUAL & ALVEOLUS & INDIVIDUAL & ALVEOLUS & INDIVIDUAL & ALVEOLUS \\
\hline$<30$ & $2 / 11(18.2)$ & $4 / 273(1.5)$ & $2 / 12(16.7)$ & $5 / 233(2.2)$ & $5 / 40(12.5)$ & $13 / 695(1.9)$ \\
\hline $30-39$ & $0 / 6(0)$ & $0 / 187(0)$ & $1 / 10(10)$ & $3 / 244(1.2)$ & $1 / 16(6.3)$ & $3 / 431(0.7)$ \\
\hline $40+$ & $2 / 8(25)$ & $10 / 228(4.4)$ & $3 / 4(75)$ & $17 / 93(18.3)$ & $6 / 16(37.5)$ & $29 / 362(8)$ \\
\hline Indet. & $0 / 1(0)$ & $0 / 5(0)$ & $0 / 2(0)$ & $0 / 16(0)$ & $1 / 4(25)$ & $1 / 30(3.3)$ \\
\hline Total & $4 / 26(15.4)$ & $14 / 693(2)$ & $6 / 28(21.4)$ & $25 / 586(4.3)$ & $13 / 76(17.1)$ & $46 / 1518(3)$ \\
\hline \multicolumn{3}{|c|}{ Age individual $\chi^{2} 6.750, p \leq 0.05$} & \multicolumn{4}{|c|}{ Sex individual $\chi^{2} 0.225, \mathrm{p} \leq 1$} \\
\hline \multicolumn{3}{|c|}{ Age alveolus $\chi^{2}$ 41.816, $\mathrm{p} \leq 0.001$} & \multicolumn{4}{|c|}{ Sex alveolus $\chi^{2} \mathbf{5 . 0 8 9 ,}, \mathbf{p} \leq \mathbf{0 . 0 2 5}$} \\
\hline
\end{tabular}

Figures given as numerator/denominator (percentage). Indet. = indeterminate age at death and/or sex.

cent) in the Da But sample compared to the Metal period sample (17.1 percent individuals, 3.0 percent alveoli) (Table 7). A test for homogeneity of AMTL frequency across age classes indicated that the distribution is statistically significantly heterogeneous in the Da But sample. Further, 7.5 percent of the anterior dentition (incisors through canines by alveoli) experienced AMTL compared to 3.4 percent of the posterior dentition (by alveoli) in this sample. Regarding sex, there were no significant differences in lesion distribution within the Da But sample, with 33.3 percent of males (4.8 percent alveoli) compared to 37.0 percent of females (6.5 percent alveoli) exhibiting AMTL. In terms of the location of AMTL, 2.8 percent of Da But period maxillary alveoli experienced AMTL compared with 6.4 percent of mandibular alveoli.

The Metal period sample also displayed an uneven distribution of AMTL, with rejection of the null hypothesis of AMTL homogeneity by age class. A slightly higher and not statistically significant frequency of posterior AMTL (3.2 percent, alveoli) was observed in the Metal period sample compared with anterior dentition (2.7 percent, alveoli). Further, more females had AMTL (individuals 21.4 percent, alveoli 4.3 percent) than males (individuals 15.4 percent, alveoli 2.0 percent), and this was statistically significant by alveolus count; 1.8 percent of maxillary alveoli showed signs of AMTL compared with 4.2 percent of mandibular alveoli. 


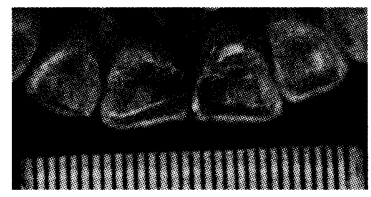

Fig. 2. Wear facets affecting the lingual (tongue) side of the central maxillary incisors. Female, 2029 years old, from Min Duc, northern Viet Nam.

in the location of ADP, with 1.4 percent of maxillary alveoli compared with 3.7 percent of mandibular alveoli having defects $\left(\chi^{2} 7.698, \mathrm{p} \leq 0.01\right)$.

Extramasticatory Wear - The frequency of wear facets attributable to extramasticatory wear - for example, using the teeth as tools (see Fig. 2 for an example) - is much more common in the Metal period sample, where 10.4 percent of individuals (3.4 percent teeth) have these facets compared with 1.3 percent of individuals (0.3 percent teeth) in the Da But sample. Only the Metal period sample data is tabulated here (Table 9). The null hypothesis that the frequency of these wear facets was homogenous across age classes was not rejected by individual but was rejected by tooth count. The reason for a relatively high frequency of facets by tooth count in the old age class and peaking in the mature age class by individual is due to a greater number of wear facets in the few older individuals. A statistically significantly higher frequency $\left(\chi^{2} 5.753, \mathrm{p} \leq 0.025\right)$ of anterior facets by tooth (7.1 percent) was observed compared to posterior facets (1.8 percent). The only individual with task wear facets in the Da But sample expressed them in the posterior dentition. Some 19.2 percent of Metal period males (5.5 percent teeth) compared to 11.1 percent of females ( 2.4 percent teeth) had extramasticatory facets, although the difference was only statistically significant by tooth count. The only individual with these wear facets in the Da But sample was a male. Looking at extramasticatory wear facets by location, 4.8 percent of Metal period maxillary teeth compared to 2.0 percent of mandibular teeth displayed them $\left(\chi^{2} 6.899, \mathrm{p} \leq 0.01\right)$.

Table 9. Frequency of Task Wear Facets

PERIOD: METAL

\begin{tabular}{|c|c|c|c|c|c|c|}
\hline \multirow[b]{2}{*}{ AGE CLASS } & \multicolumn{2}{|c|}{ MALE } & \multicolumn{2}{|c|}{ FEMALE } & \multicolumn{2}{|c|}{ TOTAL } \\
\hline & INDIVIDUAL & ТОотн & INDIVIDUAL & TOOTH & INDIVIDUAL & TоOтн \\
\hline$<30$ & $1 / 10(10)$ & $5 / 207(2.4)$ & $1 / 12(8.3)$ & $4 / 209(1.9)$ & $2 / 40(5)$ & $9 / 565(1.6)$ \\
\hline $30-39$ & $3 / 6(50)$ & $5 / 115(4.4)$ & $1 / 10(10)$ & $5 / 201(2.5)$ & $4 / 16(25)$ & $10 / 316(3.2)$ \\
\hline $40+$ & $1 / 8(12.5)$ & $18 / 181(9.9)$ & $1 / 4(25)$ & $2 / 51(3.9)$ & $2 / 16(12.5)$ & $20 / 254(7.9)$ \\
\hline Indet. & $0 / 2(0)$ & $0 / 3(0)$ & $0 / 1(0)$ & $0 / 1(0)$ & $0 / 5(0)$ & $0 / 17(0)$ \\
\hline Total & $5 / 26(19.2)$ & $28 / 506(5.5)$ & $3 / 27(11.1)$ & $11 / 462(2.4)$ & $8 / 77(10.4)$ & $39 / 1152(3.4)$ \\
\hline \multicolumn{3}{|c|}{ Age individual $\chi^{2} 4.669, \mathrm{p} \leq 0.1$} & \multicolumn{4}{|c|}{ Sex individual $\chi^{2} 0.503, \mathrm{p} \leq 1$} \\
\hline \multicolumn{3}{|c|}{ Age tooth $\chi^{2} \mathbf{2 0 . 9 3 2 , p} \leq \mathbf{0 . 0 0 1}$} & \multicolumn{4}{|c|}{ Sex tooth $\chi^{2} \mathbf{5 . 7 3}, \mathbf{p} \leq \mathbf{0 . 0 3}$} \\
\hline
\end{tabular}

Figures given as numerator/denominator (percentage). Indet. = indeterminate age at death and/or sex. 
Table io. Major long Bone Healed Fracture Frequencies by Element

\begin{tabular}{lllclll}
\hline SAMPLE & HUMERUS & RADIUS & ULNA & FEMUR & TIBIA & FIBULA \\
\hline Da But & $2 / 45(4.4)$ & $0 / 27(0.0)$ & $0 / 21(0.0)$ & $3 / 46(6.5)$ & $0 / 29(0.0)$ & $0 / 12(0.0)$ \\
Metal & $0 / 23(0.0)$ & $1 / 14(7.1)$ & $1 / 14(7.1)$ & $0 / 25(0.0)$ & $0 / 18(0.0)$ & $0 / 11(0.0)$ \\
\hline
\end{tabular}

Denominator defined minimally by preservation of the diaphysis. Figures given as numerator/ denominator (percentage).

\section{Trauma}

An analysis of trauma can provide insights into the activities an individual may have been engaged in at the time of injury or even general behaviors of the community as a whole. Further, in some cases it may be possible to make inferences regarding medical knowledge and/or intervention and, perhaps, of the level or nature of post-traumatic care. Detailed descriptions of the traumatic lesions observed in these samples, along with a discussion of proximate and ultimate causes of each lesion, are presented in Oxenham et al. (2001). Healed trauma to the radius and ulna was not observed in the Da But sample, despite good preservation of these elements (Table 10). However, 4.4 percent of humeral diaphyses showed evidence of healed trauma in the form of oblique fractures to the distal third of the diaphysis in the Da But assemblage. The only other traumatic lesions observed occurred in the femur, where 6.5 percent of the complete diaphyses displayed approximate midshaft transverse fractures with associated diaphyseal overlapping and subsequent lack of appositional healing. Two of the three cases showing this form of trauma were adults, while the remaining individual was a subadult $9 \pm 2$ years old. Poor infracranial preservation in the Metal period sample makes it difficult to assess the true frequency and patterning of trauma. The only instances of healed traumas observed were in the form of a fracture to the proximal third of a radius (7.1 percent of complete diaphyses) and the distal end of an ulna (7.1 percent of complete diaphyses). The only case of clear perimortem trauma in the Metal period was in the form of a long $(45 \mathrm{~mm})$, deep $(6.2 \mathrm{~mm})$, sharp-edged instrument cut into the right frontal boss of an adult female.

\section{Infectious Disease}

By examining the frequency and types of infectious disease, it is possible to gain insights into predisposing human behaviors, levels of general health and immunocompetence, and perhaps even a look into the quality of life of those afflicted with serious debilitating disease. Skeletal lesions of nontraumatic etiology and associated differential diagnoses have been discussed in detail by Oxenham et al. (2005). The Da But period sample includes only a single individual with a nontraumatic lesion that was likely due to some form of tumor. In the Metal period assemblage, on the other hand, 10.9 percent (6/55) of the sample displayed pathological lesions, with 50 percent of these cases including lytic cranial lesions. In the majority of cases the differential diagnoses include an infectious disease. While no definitive diagnoses have been made, mycotic (fungal) diseases were identified as being possibly responsible for 60 percent of the individuals presenting with potentially diagnostic lesions. A competing cause in a number of these same in- 
dividuals was a condition associated with compromised immunocompetence: Langerhan's cell histiocytosis. Further, two individuals likely suffered from chronic mastoid (ear) infections. Finally, even though 20 percent of the Metal period sample derived from early Bronze Age contexts, 80 percent belonged to the Dong Son proper and early Han encroachments into the region. Only the temporally later portion of the sample displayed evidence of chronic infectious disease.

\section{DISCUSSION AND CONCLUSIONS}

\section{Physiological Well-Being}

As it was not possible to carry out destructive cross-sectioning in order to isolate the etiology of cribra orbitalia (see Wapler et al. 2004), the condition is used as a signifier of generalized physiological disturbance rather than linked to a specific condition such as anemia. Individual and perhaps sample-specific differences in the remodeling of $\mathrm{CO}$ make interpretation of the frequency and patterning of this condition difficult. Nonetheless, there is an exceptionally high frequency of $\mathrm{CO}$ in both of these Vietnamese samples. Where the etiology has been identified as anemia in other samples, it has been suggested that only 50-75 percent of individuals with iron-deficiency anemia will develop skeletal responses (StuartMacadam 1991). This would potentially suggest that most individuals in these Vietnamese communities suffered from some form of physiological disturbance as children. One of the reasons for this high adult frequency of CO may be the inclusion of individuals displaying extensively remodeled lesions (closed CO). Widely cited recording protocols, such as Stuart-Macadam's (1985) and Hengen's (1971), require some degree of porosity to be present in the orbital roof before $\mathrm{CO}$ is scored as present.

The frequency of $\mathrm{CO}$ has been linked to increased mortality in at least one study. In Mittler and Van Gerven's (1994) research on Christian Kulubnarti, North Africa, they report a significant reduction in mean life expectancy for the sample with CO. For the Vietnamese samples under investigation here, there is some indication that $\mathrm{CO}$ is correlated with increased mortality in the younger age classes, with a greater proportion of older adults, particularly in the Da But sample, not showing signs of CO. However, the chief differences seen in distribution by age at death apply to varying levels of lesion remodeling where remodeled lesions are common in the older age classes, while less-remodeled cribra orbitalia is more prevalent in the younger age classes. The lower frequency of individuals displaying $\mathrm{CO}$ in the oldest age class could therefore be an artifact of either more extensive remodeling or evidence for increased life expectancy in individuals not affected by the CO.

What are the underlying etiological causes for the high frequency of cribra orbitalia, all manifestations included, in the Vietnamese populations? It is very difficult to isolate any one cause or even the varying contributions of multiple-likely synergistic - factors. The only fairly definite common factors in both periods are that these communities were essentially sedentary, living in a subtropical environment, and had a coastal-riverine economic focus. Sedentism, of course, does not necessarily imply a significant or even minor agricultural component to the subsistence economy. Nonetheless, the effects of sedentism appear to be the one 
common global factor in the increased frequency of porotic hyperostosis (including cribra orbitalia) beginning at the start of the Holocene (Stuart-Macadam 1998). The fact that these Vietnamese communities were situated in the subtropics, with the associated huge potential for parasitic infestation, needs to be considered. It is also worth noting that coastal and marine-based communities can suffer from high parasitic loads (Walker 1986). It is also probable that the populations sampled here were affected by hereditary anemic conditions, such as various forms of thalassemia, as has been shown to be the case at Khok Phanom Di in neighboring Thailand (see Tayles 1996). The role played by dietary deficiencies in young growing children and the effects of anemic mothers, also likely experiencing various degrees of parasitic infestation and perhaps genetically derived anemia, should also be considered. In terms of adult health, it is worth noting that very high rates of anemia are reported in the children of modern northern Vietnamese communities (C. K. Nguyen et al. 1995), with little demonstrable negative effect on the health of subsequent adults. Returning to the ancient Vietnamese samples, even if there was a high mortality rate among subadults with $\mathrm{CO}$, it does not change the observation that most of the adults also had the condition as children.

The apparent-albeit statistically nonsignificant-higher frequency of linear enamel hypoplasia in the younger age class of both samples is intriguing. A smaller proportion of older individuals displaying LEH might suggest increased chances of survival to old age for those who did not suffer the stresses causing it. It is unlikely that the lower frequency of LEH in older individuals is an artifact of LEH events being lost through wear, because extremely worn teeth were not included in the study sample. When only examining those individuals that survived the LEHsensitive years, it would appear that there is a correlation between survival to older age and absence of LEH in both samples. Such a relationship between the presence of LEH and decreased mean age at death has been noted in a number of studies (Duray 1996; Goodman and Armelagos 1988; Saunders and Keenleyside 1999).

While it is difficult to compare LEH frequencies between geographically disparate samples due to differential and ultimately unknowable baseline LEH variation (see Zhou and Corruccini 1998), it is still worthwhile looking at how the Vietnamese levels compare with other studies. The overall frequency of LEH in the Vietnamese samples is not unusually high relative to some bioarchaeological studies. For instance, very high enamel hypoplasia frequencies have been reported for maxillary canines (98.4 percent) and mandibular canines (98.2 percent) in the mid-Holocene Ra's al-Hamra-5 sample from Oman (Mack and Coppa 1992). However, the Vietnamese canine LEH frequency does appear somewhat elevated with respect to other East and Southeast Asian studies. East and Southeast Asian analyses of LEH show a great deal of variation in reported frequencies. For example, Yamamoto (1992) has examined the frequency of permanent mandibular canine LEH in Japanese from the Jomon period, beginning some 10,000 years B.P. through to the modern period. The foraging Jomon sample displayed a LEH frequency of 48.1 percent, the agricultural and foraging Kofun sample 36.4 percent, the early modern urban Edo sample 65.1 percent, and the modern sample exhibited an LEH frequency of 39.5 percent. Yamamoto cited variations in subsistence, sanitation, and population density as the chief etiological factors involved in the variation in $\mathrm{LEH}$ frequency over time. 
Tayles (1992) reports that 50 percent of maxillary and 48 percent of mandibular permanent canines displayed LEH in the coastal site of Khok Phanom Di in Thailand (4000 to 3500 years B.P.). This finding is somewhat intriguing in face of comments by Higham (1989) that the Khok Phanom Di habitat was particularly favorable to its inhabitants. Nelson (1999) reports that 30 percent of individuals with maxillary canines displayed LEH, while 45.9 percent of individuals with mandibular canines had LEH in the site Noen U-Loke in Thailand (2300 to 1700 years B.P.). The frequency of adult individual LEH at Non Nok Tha, Thailand (5500 to 3000 years B.P.), is 16.7 percent for the maxillary canines and 21.4 percent for the mandibular canines (Douglas 1996). For an assemblage from Ban Chiang, Thailand (5600 to 1700 years B.P.), the frequency of adult individual canine LEH is 7.7 percent for the maxillary and 6.3 percent for the mandibular dentition (Pietrusewsky and Douglas 2002).

The chief subsistence economies of the inhabitants of these sites in Thailand, in particular, seem to display a general pattern with regard to LEH frequency. Noen U-Loke can be described as having a predominantly agricultural subsistence economy and a comparatively elevated frequency of LEH, while the Ban Chiang and Non Nok Tha sites are perhaps best described as mixed (foraging with agricultural and/or horticultural components) and have fairly low LEH frequencies by Southeast Asian standards. However, Khok Phanom Di, with a predominantly foraging economy, has relatively elevated levels of LEH. Further, the Japanese Jomon foragers displayed a higher frequency of LEH relative to the temporally later agricultural period. Nonetheless, the urban Edo sample displayed the highest level of $\mathrm{LEH}$, and the individuals comprising this sample would have experienced elevated levels of population density and lowered levels of public sanitation.

Accepting that high levels of canine LEH are potentially reflective of an agricultural subsistence economy is inconsistent with the archaeological evidence from the Da But period assemblage. However, both Da But and Metal period populations were likely quite sedentary, so factors associated with sedentism and perhaps population density may be important in the level of LEH present in these Vietnamese samples. Further, the coastal/estuarine orientation of these communities may have exposed them to high parasitic loads (see Walker 1986). With respect to a possible positive correlation between sedentism and population density, see Webb's (1995) results for prehistoric Australia. Webb reports permanent maxillary canine LEH frequencies for several regions of the prehistoric Australian continent. There was a clear tendency for the frequency of LEH to be low (20.728.8 percent) in the arid regions of Australia and higher (37.6-45.6 percent) in the more fertile and more densely populated regions. Webb favors differences in weaning customs between arid and fertile regions to account for the observed differences in LEH frequency. However, it is probably more likely that the clear and marked environmental, climatic, and settlement pattern differences between these regions - in particular, population density - were more important underlying causes in LEH frequency variations.

What can be said of the Da But period and Metal period samples is that the overall level of well-being of both assemblages appears to be similar, at least with respect to $\mathrm{LEH}$ frequency. How elevated their respective $\mathrm{LEH}$ levels are relative to the baseline level for populations from which they are sampled cannot be de- 
termined and is ultimately unknowable. Moreover, the specific etiological factors responsible for these $\mathrm{LEH}$ levels must remain unknown. However, it is important to remember that there is some evidence indicating that those individuals without LEH tended to live longer than those individuals with LEH. This again would tend to suggest that the causes of LEH had a deleterious affect on the health of these ancient Vietnamese. Finally, comparing the frequency of LEH in the Da But and Metal period samples to other East and Southeast Asian samples indicates that the Vietnamese frequency of LEH is somewhat elevated. If the frequency of LEH does correlate with the level of physiological stress a population endured, it would appear that the Vietnamese samples endured somewhat higher levels of stress than did other populations thus far sampled in the tropical Southeast Asian context.

\section{Oral Health}

The frequency of carious lesions is very low in both samples and would suggest that agriculturally oriented populations are not being sampled here (see Oxenham et al. 2006). Nonetheless, this view needs to be treated with caution given the diverse range of factors potentially contributing to oral health (Hillson 2001; Larsen 1997). Historical (Holmgren 1980) and archaeological (Higham 1989) data suggest an increase in rice production in the Metal period, particularly during the Dong Son period with Han colonization. The frequency of carious lesions would not tend to support that view, although the more youthful nature of the Metal period sample may be relevant with respect to an age-dependent disease such as caries. Further, a higher frequency of caries was seen in the younger age groups of the Metal period sample, which may be a reflection of secular changes within the sample. The Da But sample, on the other hand, displayed an expected increase in lesions with increasing age at death. If the suggestion from archaeological and historical data is correct, it may be the case that rice is not particularly cariogenic. A number of studies have suggested the low cariogenicity or poor caries-inducing potential of rice diets (Krasse 1985; Sreebny 1983; Tayles et al. 2000). A marine component in the diets of both periods has been suggested, and in fact the Con Co Ngua diet would appear to be marine dependent (Yasutomo et al. n.d.), and such diets are known to be cariostatic (Kelley et al. 1991; Larsen et al. 1991; Sealy et al. 1992; Walker and Erlandson 1986). Females had higher frequencies of carious lesions in both samples, but this was only significant by tooth count in the Metal period sample. A higher frequency of lesions in females is not an uncommon finding in bioarchaeological studies and is often attributed to differences in diet or eating behavior (Larsen et al. 1991). Such differences, however, do not necessarily imply any particular social hierarchy by gender (Walker and Hewlett 1990).

The distribution of lesions on the crown in each sample is expected given the low overall frequency of lesions and the differential susceptibility of the tooth to lesions (see discussion in Hillson 2001). Interestingly, both samples displayed a high proportion of caries affecting the root and/or cervix of the tooth. An increase in lesions at this location can be seen as associated with a more agriculturally oriented diet (see Molnar and Molnar 1985; Moore 1993), which may be 
consistent with expectations for the Metal period but not the Da But period sample. However, continuous tooth eruption in high tooth wear situations can expose this region of the tooth to acidogenic bacteria.

Antemortem (AMTL) tooth loss is subject to potentially much broader and complex etiological considerations than carious lesions. The significantly greater frequency of AMTL and the favoring of the anterior dentition in the Da But sample may be related to the practice of tooth ablation, which has been reported at least for prehistoric Thailand (Tayles 1997). The tendency for other Da But sample pathologies such as alveolar defects of pulpal origin and pulp chamber exposure (not reported in this study) to favor the posterior dentition would tend to support the idea of deliberate ablation. However, the observation that AMTL increases with age at death for both samples is difficult to reconcile with the tooth ablation hypothesis.

The observation of increasing frequencies of alveolar defects of pulpal origin (ADP) and increasing age at death for both samples was expected. The near equivalence in the frequency of ADP between the anterior and posterior dentition of the Metal period sample is intriguing. It is likely that this is related to the much higher frequency of the evidence for task wear facets in the Metal period sample. Much of the artificial tooth wear seen in the Metal period sample occurs in the anterior dentition, and a common sequel to advanced extramasticatory tooth wear is pulp chamber exposure and subsequent abscessing or granuloma formation. Clear associations between the frequency of task wear facets and age at death would not be expected due to the rapid loss of teeth in older age and thus loss of task wear faceted teeth. Nonetheless, the association is apparent at least by tooth count, although the reason for this is a high number of faceted teeth in the few older individuals with such facets. Whatever activities these people were engaging in with their teeth-and it must remain highly speculative for the time being-it is males who appear to have been more involved.

\section{Trauma}

Due to poor infracranial preservation of the Metal period sample, it is difficult to assess the low apparent frequency of trauma in this assemblage. The two forearm fractures seen in this assemblage are the most common form of trauma seen in Southeast Asia (Oxenham et al. 2001) and are quite consistent with either misadventure or interpersonal violence. In addition to historical (e.g., Taylor 1983) evidence for frequent warfare in the region during this period, grave goods in many of the sites sampled in this study contained spear- and arrowheads, javelins, and axes (Oxenham 2000) suggestive of the potential to engage in acts of violence. Nonetheless, the single example of potential interpersonal violence as represented by the frontal wound in an adult Metal period female would seem at odds with the historical and archaeological evidence for frequent conflict in the region. Less than ideal sampling of Metal period burial sites may be a factor to be considered.

A very different picture is seen when examining the Da But sample. Despite good infracranial preservation, it is the larger and more robust bones that were at risk. While 7.4 percent of this sample displays evidence of some form of healed major trauma, these lesions could all have been the result of falls through misadventure. While such traumatic injury could have been caused by way of interper- 
sonal violence, the overall pattern of trauma and the lack of obvious weaponry during this period do not support this hypothesis at present. Oxenham et al. (2001) have pointed out that the risk of serious trauma was greater at Con Co Ngua than any other Southeast Asian assemblage sampled to date. It is difficult to determine what types of behavior placed these Da But culture individuals at such a risk of serious injury. As noted at the beginning of this paper, the region was home to numerous large animals that may have been hunted. Some evidence that might be interpreted as suggesting such hunting comes from stag horns placed in the graves of several individuals.

What can be inferred with respect to immediate medical intervention or posttraumatic care? Relatively minor trauma in the form of fractures to the forearms and humerus can readily heal even without medical intervention in the form of splinting, although this does not rule out medical intervention in either time period. The healed thigh fractures of several individuals in the Da But sample represent potentially much more serious injuries. However, again it is possible that these injuries would have healed without the use of splinting. Lovell (1990) has described an adult male free-ranging mountain gorilla with multiple healed fractures, including the midshaft of the left femur, illustrating the ability of primates to survive and adapt to serious trauma without the benefit of medical systems.

\section{Infectious Disease}

The skeletal evidence for infectious disease is present only in the Metal period sample and then only in individuals from the terminal (Dong Son) Bronze phase. An osteological paradox could be invoked for the Da But sample, whereby there is a lack of infectious disease because affected individuals died before experiencing a skeletal reaction. However, the older age distribution of the Da But sample would tend to indicate that this was not the case.

Given the probable types of disease identified in the Metal period sample, including the possibility of immune system disorders, there are several scenarios accounting for the emergence of infectious disease at this time that require discussion. The first possibility relates to the evolutionary history of infectious diseases. Recently, scholars have pointed out that pathogens will tend to evolve toward higher virulence particularly when the pathogens involved are either waterborne or vector borne (Ewald 1994, 2003). Archaeological evidence for the Da But period suggests the domestication of large vertebrates such as buffalo and pigs, as well as a reduced level of mobility or a move to increased sedentism. It is not improbable that the closer association between humans and domesticated animals, in addition to the general health costs associated with sedentism, led to the development of a range of infectious diseases at this time. With time, these "new" pathogens evolved into more virulent forms that had a negative impact on the health of Metal period communities.

A second scenario relates to the observation that the differential diagnosis of 60 percent of those Metal period individuals with potentially specifiable diseases included some form of fungal infection. Such infections are not due to direct transmission between human hosts but are generally caused by incidental introduction of the pathogen by way of traumatic inoculation (a cut, for instance), inhalation of disturbed spores, or even via a vector such as the bamboo rat in the 
case of Penicilliosis marneffei, for example. It is often the case that pathogens that do not generally target humans are particularly virulent when they do infect people. Well-known examples of this include Rocky Mountain spotted fever and rabies. The archaeologically and historically documented increase in population density, land clearing, and development of intensive rice agriculture in the latter stages of the Metal period would have provided ample opportunity for incidental infection by way of fungal pathogens.

The third factor to consider is the level of immunocompetence in the Metal period sample as a whole. If the levels of enamel hypoplasia and cribra orbitalia can be used as some gauge of the strength of the immune response system in adulthood, it would seem that immunocompetence was somewhat compromised in both periods. However, the effects, whether single or combined, of evolving pathogen virulence and increased contact with pathogens not generally known to humans during the earlier period of low population density and infrequent land clearing and cultivation associated with a poor immune response may have taken their toll on Metal period populations. Added to this is a fourth factor in the form of massive population movements into the region at the time infectious disease first appears. Much of this demographic upheaval was in the form of Han military campaigns and colonization efforts beginning during the Dong Son period, or the terminal phase of the Bronze Age.

\section{SUMMARY}

Despite major economic, demographic, and social change in northern Viet Nam between 6000 and 2000 years B.P., biological changes have been minimal in terms of baseline health markers in the form of oral and physiological well-being. It was suggested that the lack of a marked difference in oral health may have been due to the low cariogenicity of rice agricultural diets and/or that the majority of rice was exported rather than eaten. However, major differences are observed with respect to some oral behavioral markers, the patterning and frequency of traumatic injury, and the evidence for infectious disease. It has been argued that the level of cribra orbitalia in both samples is relatively high by any standards, and younger individuals were at somewhat greater risk of dying if they had CO. Moreover, elevated levels of canine enamel hypoplasia are associated with a reduced age at death in each sample. Given the general equivalence of each sample for these general measures of health, a range of scenarios was discussed in an attempt to understand the emergence of infectious disease in the latter phases of the Metal period. It was not argued that the presence or absence of infectious disease had any particular health or ill-health consequences for the samples as a whole. However, factors including the evolution of greater pathogen virulence over time, increased contact with pathogens through increasing population density, changing land use practices, introduction of new pathogens through human demographic upheavals, and decreased immunocompetence in the Metal period were examined. Specific behavioral differences were also seen between each sample, with a much greater level of serious traumatic injury occurring during the Da But period. While the cause or causes of this finding are unclear, it may be related to large-game hunting, although a case that some may be due to interpersonal vio- 
lence cannot be ruled out. Further differences in terms of oral behavior are seen in the possible though unconfirmed practice of anterior tooth ablation in the Da But period and use of the anterior dentition, particularly by males, for specific tasks in the Metal period sample. Clearly, the major archaeologically and historically documented behavioral changes occurring in Viet Nam in the latter half of the Holocene have left clear and in some cases specifiable biological signatures, regardless of how the health implications of these skeletal and dental signs are interpreted.

\section{ACKNOWLEDGMENTS}

I would like to thank the staff at the Institute of Archaeology, Hanoi, Viet Nam, and Dr. Nguyen Kim Dung, Professor Nguyen Lan Cuong, and Nguyen Kim Thuy in particular for all their help and assistance.

\section{REFERENCES}

BuI VINH

1980 Bao cao khai quat, di tich van hoa Da But, dia diem khao co hoc: Con Co Ngua (ThanhHoa) (Cultural Vestiges at Da But Archaeological Site at Con Co Ngua [Thanh Hoa]). Unpublished excavation report, Institute of Archaeology, Hanoi, Viet Nam.

1991 The Da But culture in the Stone Age of Vietnam. Bulletin of the IndoPacific Prehistory Association $10: 127-131$.

1994 On the post-Hoabinhian period in the Stone Age of Vietnam. Vietnam Social Sciences $5(43): 35-39$.

1996 Da But Culture in the post-Hoabinhian in Vietnam. Vietnamese Studies 120(2):23-29.

Bulbeck, D., M. Oxenham, L. C. Nguyen, and K. T. Nguyen

2003 Implications of the terminal Pleistocene skull from Hang Muoi, North Vietnam. Paper presented at the 2003 Australian Archaeological Association Conference, Jindabyne, New South Wales, 5 December.

COHEN, M. N.

1997 Does paleopathology measure community health? A rebuttal of "the osteological paradox" and its implications for world prehistory, in Integrating Archaeological Demography: Multidisciplinary Approaches to Prehistoric Population: 243-260, ed. R. R. Paine. Center for Archaeological Investigations Occasional Paper No. 24. Southern Illinois University at Carbondale.

De Crespigny, R.

1990 Generals of the South: The Foundation and Early History of the Three Kingdoms State of Wu. New Series No. 16. Canberra: Australian National University, Faculty of Asian Studies.

1996 South China in the Han period, in Ancient Chinese and Southeast Asian Bronze Age Cultures: The Proceedings of a Conference Held at the Edith and Joy London Foundation Property, Kiola, NSW, 8-12 February 1988: 759-768, ed. F. D. Bulbeck and N. Barnard. Taipei: SMC Publishing.

DeMETER, F.

1999 A Wadjak presence in northern Vietnam. Paper presented at the International Colloquium on Southeast Asian Prehistory in the 3rd Millennium. Penang, Malaysia, September.

Demeter, F., E. Peyre, and Y. Coppens

2000 Présence probable de forme de type Wadjak dans la baie fossile de Quyhn Luu au Nord Viêt Nam sur le site de Cau Giat. Compes Rendus de l'Acadamie de Science 330:451-456.

Dias, G., AND N. TAYLES

1997 "Abscess cavity": A misnomer. International Journal of Osteoarchaeology 7:548-554.

DOMETT, K. M.

2001 Health in Late Prehistoric Thailand. BAR International Series 946. Oxford: Archaeopress. 
Douglas, $M$.

1996 Paleopathology in human skeletal remains from the pre-Metal, Bronze and Iron Ages, Northeastern Thailand. Unpublished Ph.D. diss. University of Hawai'i, Honolulu.

Duray, S. M.

1996 Dental indicators of stress and reduced age at death in prehistoric native Americans. American Journal of Physical Anthropology 99:275-286.

EWALD, P. W.

1994 The evolution of virulence and emerging diseases. Journal of Urban Health 75(3):480491.

2003 Evolution and ancient diseases: The roles of genes, germs, and transmission modes, in Emerging pathogens: archaeology, ecology and evolution of infectious disease: 117-124, ed. C. Greenblatt and M. Spigelman. Oxford: Oxford University Press.

Federation Dentaire International

1982 An epidemiological index of developmental defects of dental enamel (DDE Index). International Dental Journal 32(2) : 159-167.

Goodman, A. H.

1993 On the interpretation of health from skeletal remains. Current Anthropology 34:281288.

Goodman, A. H., and G. J. Armelagos

1988 Childhood stress and decreased longevity in a prehistoric population. American Anthropologist 90 : 936-944.

Gorman, C.

1971 The Hoabinhian and after: Subsistence patterns in Southeast Asia during the late Pleistocene and early Recent periods. World Archaeology 2(3):300-320.

Harpending, $\mathrm{H}$.

1990 Review of Health and the Rise of Civilization, by Mark N. Cohen. American Ethnologist $17: 799$.

Hengen, O. P.

1971 Cribra orbitalia: Pathogenesis and probable etiology. Journal of Comparative Human Biology $22: 57-75$.

Higham, C.F.W.

1989 The Archaeology of Mainland Southeast Asia. Cambridge, UK: Cambridge University Press.

1996 The Bronze Age of Southeast Asia. Cambridge, UK: Cambridge University Press.

Hillson, S.

2001 Recording dental caries in archaeological remains. International Journal of Osteoarchaeology $11: 249-289$.

Holmgren, J

1980 Chinese Colonisation of Northern Vietnam: Administrative Geography and Political Development in the Tongking Delta, First to Sixth Centuries A.D. Canberra: Australian National University.

Kelley, M. A., D. R. Levesque, And E. Weidl

1991 Contrasting patterns of dental disease in five early northern Chilean groups, in Advances in Dental Anthropology: 203-213, ed. M. A. Kelley and C. S. Larsen. New York: Wiley-Liss.

Krasse, B.

1985 The cariogenic potential of foods: A critical review of current methods. International Dental Journal $35: 36-42$.

LARSEN, C. S.

1997 Bioarchaeology: Interpreting Behavior from the Human Skeleton. Cambridge, UK: Cambridge University Press.

Larsen, C. S., R. Shavit, and M. C. Griffin

1991 Dental caries evidence for dietary change: An archaeological context, in Advances in Dental Anthropology: 179-202, ed. M. A. Kelley and C. S. Larsen. New York: Wiley-Liss.

Lovell, N. C.

1990 Patterns of injury and illness in Great Apes: a skeletal analysis. Washington and London: Smithsonian Institution Press. 
Lu, G. D., AND J. NeEdham

1993 Diseases of antiquity in China, in The Cambridge World History of Human Disease: 345354, ed. K. F. Kiple. Cambridge: Cambridge University Press.

MACK, M. E., AND A. COPPA

1992 Frequency and chronological distribution of enamel hypoplasias from the Ra's al-Hamra5 (RH5) skeletal collection (Oman), in Recent Contributions to the Study of Enamel Developmental Defects: 131-141, ed. A. H. Goodman and L. L. Capasso. Monographic Publications 2, Journal of Paleopathology.

Matsumura, H., N. L. Cuong, N. K. Thuy, and T. Anezaki

2001 Dental morphology of the early Hoabinian, the Neolithic Da But and the Metal Age Dong Son cultural people in Vietnam. Zeitschrift für Morphologie und Anthropologie 83:5973.

Mittler, D. M., ANd D. P. van Gerven

1994 Developmental, diachronic, and demographic analysis of cribra orbitalia in the medieval Christian populations of Kulubnarti. American Journal of Physical Anthropology 93:287297.

Molnar, S., AND I. Molnar

1985 Observations of dental diseases among prehistoric populations of Hungary. American Journal of Physical Anthropology 67:51-63.

MoOre, W. F.

1993 Dental caries in Britain from Roman times to the nineteenth century, in Food, Diet and Economic Change Past and Present: 50-61, ed. C. G. Geissler and D. F. Oddy. Leicester, UK: Leicester University Press.

NELSEN, K. M.

1999 The Dental Health of the People from Noen U-Loke: A Prehistoric Iron Age Site in Northeast Thailand. M.A. thesis. University of Otago, New Zealand.

Nguyen, C. K., Y. Hofvander, B. T. Duong, N. D. Dao, and V. S. Hoang

1995 Child anaemia in some areas of North Vietnam. Vietnamese Studies 118(4):19-28.

NGUYen, K. S.

1996 The Sonvian in the prehistory of Vietnam and Southeast Asia. Vietnamese Studies 120(2): 7-22.

1997 In the framework of the maritime culture of Vietnam: The prehistoric maritime culture of the northeast. Vietnamese Studies 123(1):87-116.

Nguyen, K. T.

1990 Ancient human skeletons at Con Co Ngua. Khao Co Hoc 3:37-48.

1998 Human remains from Con Co Ngua: A Da But culture site. Paper presented at the 16th Congress of the Indo-Pacific Prehistory Association, Melaka, Malaysia 1-7 July.

Nguyen, L. C.

1985 Two precious ancient crania discovered in the west of Thanh Hoa Province. Vietnam Social Sciences $2: 125-129$.

1992 A reconsideration of the chronology of hominid fossils in Vietnam, in The Evolution and Dispersal of Modern Humans in Asia: 321-335, ed. T. Akazawa, K. Aoki, and T. Kimura. Tokyo: Hokusen-Sha.

1996 Anthropological Characteristics of Dong Son Population in Vietnam. Hanoi: Social Sciences Publishing House.

NGuYen, T. D.

1995 Geography of Vietnam: Natural, Human, Economic. Hanoi: Gioi Publishers.

Olivier, G.

1966 Craniometrie des Indochinois. Bulletin de la Société Anthropologique 9(11):67-90.

ORTNER, D. J.

1992 Skeletal paleopathology: Probabilities, possibilities and impossibilities, in Disease and Demography in the Americas: 5-13, ed. J. W. Verano and D. H. Ubelaker. Washington, D.C.: Smithsonian Institution Press.

Oxenham, M. F., C. Locher, L. C. Nguyen, and K. T. Nguyen

2002 Identification of Areca catechu (betel nut) residues on the dentitions of Bronze Age inhabitants of Nui Nap, northern Vietnam. Journal of Archaeological Science 29(9): 909-915. 
Oxenham, M. F., K. T. Nguyen, and L. C. Nguyen

2005 Skeletal evidence for the emergence of infectious disease in Bronze and Iron Age northern Vietnam. American Journal of Physical Anthropology 126:359-376.

Oxenham, M. F., L. C. Nguyen, and K. T. Nguyen

2002 Oral health in northern Vietnam: Neolithic through Bronze periods. Bulletin of the IndoPacific Prehistory Association 22(6): 121-134.

2006 The oral health consequences of the adoption and intensification of agriculture in Southeast Asia, in Bioarchaeology of Southeast Asia: 263-289, ed. M. Oxenham and N. Tayles. Cambridge, UK: Cambridge University Press.

Oxenham, M. F., I. Walters, L. C. Nguyen, and K. T. Nguyen

2001 Case studies in ancient trauma: Mid-Holocene through Metal periods in northern Vietnam, in The Causes and Effects of Biological Variation: 83-102, ed. M. Henneberg and J. Kilgariff. Adelaide: Australasian Society for Human Biology.

Oxenham, M., and N. TAyles, N., eds.

2006 Bioarchaeology of Southeast Asia. Cambridge, UK: Cambridge University Press.

Pietrusewsky, M.

1988 Multivariate comparisons of recently excavated Neolithic human crania from Thanh Hoa Province, Socialist Republic of Vietnam. International Journal of Anthropology 3:267283.

Pietrusewsky, M., And M. T. Douglas

2002 Ban Chiang, a Prehistoric Village Site in Northeast Thailand I: The Human Skeletal Remains. University Museum Monograph 111. Philadelphia: University of Pennsylvania.

Pietrusewsky, M., Y. Y. Li, X. Q. Shao, and Q. Q. Nguyen

1992 Modern and near modern populations of Asia and the Pacific: A multivariate craniometric interpretation, in The Evolution and Dispersal of Modern Humans in Asia: 532-558, ed. T. Akazawa, K. Aoki, and T. Kimura. Japan: Hokusen-Sha.

Saunders, S. R., and A. Keenleyside

1999 Enamel hypoplasia in a Canadian historic sample. American Journal of Human Biology 11: 513-524.

SCHAFER, E. H.

1967 The Vermilion Bird: T'ang Images of the South. Berkeley: University of California Press.

Sealy, J. C., M. K. Patrick, A. G. Morris, and D. Alder

1992 Diet and dental caries among later Stone Age inhabitants of the Cape Province, South Africa. American Journal of Physical Anthropology 88:123-134.

SREebny, L. M.

1983 Cereal availability and dental caries. Community Dentistry and Oral Epidemiology 11(3) : 148-155.

Steckel, R. H., ANd J. C. Rose, eds.

2002 The Backbone of History: Health and Nutrition in the Western Hemisphere. Cambridge, UK: Cambridge University Press.

Stuart-Macadam, P. L.

1985 Porotic hyperostosis: Representative of a childhood condition. American Journal of Physical Anthropology 6:391-398.

1991 Anaemia in Roman Britain: Poundbury Camp, in Health in Past Societies: Biocultural Interpretations of Human Skeletal Remains in Archaeological Contexts: 101-113, ed. H. Bush and M. Zvelebil. BAR International Series 567.

1998 Iron deficiency anemia: Exploring the difference, in Sex and Gender in Paleopathological Perspective: 45-63, ed. A. L. Grauer and P. Stuart-Macadam. Cambridge, UK: Cambridge University Press.

TAYLES, N.

1992 The People of Khok Phanom Di: Health as Evidence of Adaptation in a Prehistoric Southeast Asian Population. Ph.D. diss. University of Otago, New Zealand.

1996 Anemia, genetic diseases, and malaria in prehistoric Mainland Southeast Asia. American Journal of Physical Anthropology $101: 11-27$.

1997 Tooth ablation in prehistoric Southeast Asia. International Journal of Osteoarchaeology $6: 333-345$.

1999 The People. Vol. 5 of The Excavation of Khok Phanom Di: A Prehistoric Site in Central Thailand. London: Society of Antiquaries of London. 
Tayles, N., K. Domett, and K. Nelsen

2000 Agriculture and dental caries? The case of rice in prehistoric Southeast Asia. World Archaeology $32: 68-83$.

TAYLOR, K. W.

1983 The Birth of Vietnam. Berkeley: University of California Press.

WALKER, P. L.

1986 Porotic hyperostosis in a marine-dependent California Indian population. American Journal of Physical Anthropology 69(3):345-354.

WALKer, P. L., AND J. M. ERLANDSON

1986 Dental evidence for prehistoric dietary change on the northern Channel Islands, California. American Antiquity 51(2):375-383.

WAlker, P. L., AND B. S. Hewlett

1990 Dental health, diet and social status among Central African foragers and farmers. American Anthropologist 92(2):383-398.

Wapler, U., E. Eric Crubézy, and M. Schultz

2004 Is cribra orbitalia synonymous with anemia? Analysis and interpretation of cranial pathology in Sudan. American Journal of Physical Anthropology 123:333-339.

WeBb, S.

1995 Palaeopathology of Aboriginal Australians: Health and Disease across a Hunter-Gatherer Continent. Cambridge, UK: Cambridge University Press.

Wood, J. W., G. R. Milner, H. C. Harpending, and K. M. Weiss

1992 The osteological paradox. Current Anthropology 33(4):343-370.

Yамамото, $M$.

1992 Secular trends of enamel hypoplasia in Japanese from the prehistoric to modern period, in Recent Contributions to the Study of Enamel Developmental Defects: 231-238, ed. A. H. Goodman and L. L. Capasso. Journal of Paleopathology Monographic Publications 2.

Yasutomo, Y., N. W. Bower, M. F. Oxenham, L. C. Nguyen, and K. T. Nguyen

(n.d.) Reconstruction of $\mathrm{Da}$ But period diets in northern Vietnam using stable isotope analysis: Preliminary findings. Unpublished report.

Zhou, L. M., AND R. S. Corruccini

1998 Enamel hypoplasias related to famine stress in living Chinese. American Journal of Human Biology 10:723-733.

\section{ABSTRACT}

A bioarchaeological analysis of human remains from Con Co Ngua, a Da But culture period cemetery site in northern Viet $\operatorname{Nam}(n=96)$, and an aggregated sample from 11 sites, mostly from the Red River delta region $(n=96)$ representing the emerging Metal period in the same region, is carried out. This study focuses on a range of skeletal and dental signatures of both health and behavior, including carious lesions, antemortem tooth loss, alveolar defects of pulpal origin, dental task wear facets, cribra orbitalia, linear enamel hypoplasia, trauma, and chronic infectious disease. The findings of reasonably good oral health may be reflective of a lack of agricultural products in the diet and/or the low cariogenicity of rice. The physiological health of the samples was found to be compromised, with an elevated mortality among younger individuals that expressed evidence of physiological disturbance as measured by cribra orbitalia and/or linear enamel hypoplasia. The nature and frequency of trauma in both periods was not necessarily indicative of specific behaviors, with general misadventure and interpersonal violence as competing causes. The evidence for chronic infectious disease is apparent only in the Metal period and may be related to a range of factors, some of which include the effects of migration, changes to land use patterns, and/or the evolution of increased pathogen virulence. KeYwords: Con Co Ngua, Da But period, Metal period, Viet Nam. 